\title{
Hydrogen incorporation in enstatite in the system $\mathrm{MgO}-\mathrm{SiO}_{2}-\mathrm{H}_{2} \mathrm{O}-\mathrm{NaCl}$
}

\author{
Roland Stalder · Andreas Kronz · Klaus Simon
}

Received: 1 February 2008/Accepted: 4 April 2008/Published online: 16 April 2008

(C) The Author(s) 2008

\begin{abstract}
The incorporation of hydrogen in enstatite in a hydrous system containing various amounts of $\mathrm{NaCl}$ was investigated at $25 \mathrm{kbar}$. The hydrogen content in enstatite shows a clear negative correlation to the $\mathrm{NaCl}$-concentration in the system. The most favourable explanation is the reduction of water fugacity due to dilution. Other reasons for the limited hydrogen incorporation at high $\mathrm{NaCl}$ levels, such as a significant influence of $\mathrm{Na}^{+}$on the defect chemistry or an exchange between $\mathrm{OH}^{-}$and $\mathrm{Cl}^{-}$in enstatite, appear much less important. A partition coefficient $D_{\mathrm{Na}}$ En/Fluid $=0.0013$ could be determined, demonstrating that $\mathrm{Na}$ is less incompatible in enstatite than $\mathrm{H}$. The new results support the idea that dissolved components have to be considered when the total hydrogen storage capacity in nominally anhydrous minerals is estimated, especially in geological settings with high levels of halogens, such as subduction zones.
\end{abstract}

Keywords Enstatite $\cdot$ Hydrogen incorporation ·

Water activity $\cdot$ Sodium $\cdot$ Chlorine

\section{Introduction}

Significant traces of hydrogen are incorporated into nominally anhydrous minerals of the Earth's upper mantle

Communicated by J. Hoefs.

R. Stalder · A. Kronz $\cdot$ K. Simon

Geowissenschaftliches Zentrum der Universität Göttingen,

Goldschmidtstraße 1, 37077 Göttingen, Germany

R. Stalder $(\bowtie)$

Institut für Mineralogie und Petrographie, Universität Innsbruck, Innrain 52, 6020 Innsbruck, Austria

e-mail: rstalde@gwdg.de
(Kitamura et al. 1987; Bell and Rossman 1992; Ingrin and Skogby 2000; Grant et al. 2007), influencing many physical properties (e.g. Mackwell et al. 1985; Karato 1990; Mei and Kohlstedt 2000; Wang et al. 2006; Yoshino et al. 2006) and mantle processes, such as partial melting. More than half of this hydrogen inventory is hosted in orthopyroxene (Grant et al. 2007), which exhibits a rather narrow range around $200 \mathrm{ppm}(\mathrm{wt}) \mathrm{H}_{2} \mathrm{O}$ in mantle xenoliths from continental alkali basalts and kimberlites (Grant et al. 2007). In contrast, natural mantle orthopyroxenes from sub-arc settings show a much higher variability $\left(40-260\right.$ ppm $\mathrm{H}_{2} \mathrm{O}$ ) and generally lower water contents (Peslier et al. 2002). The incorporation of water in orthopyroxene has also been investigated in many experimental studies (Rauch and Keppler 2002; Stalder 2004; Stalder et al. 2005; Mierdel et al. 2007), where up to several thousands ppm $\mathrm{H}_{2} \mathrm{O}$ have been reported. In none of the previous studies the effect of dissolved salts in the coexisting fluids has been examined. $\mathrm{NaCl}$ is an important constituent of seawater and allows substantial $\mathrm{Cl}$-incorporation in the basaltic oceanic crust and during serpentinization of mantle rocks at mid ocean ridges. Upon serpentine breakdown the incorporated chlorine is subsequently released into fluid phases during subduction processes (Scambelluri et al. 1997, 2004) and may affect the water activity in the mantle wedge. In this study the effect of $\mathrm{NaCl}$ on the hydrogen incorporation in pure enstatite is investigated. As a by-product we present an upper value for Cl-solubility in enstatite, and discuss consequences for the global chlorine cycle.

\section{Experimental and analytical procedure}

Orthopyroxene crystals were synthesised applying a method similar to Stalder (2002). The starting mixtures consisted of 
an enstatite + quartz mixture (3:1 by weight), to which solid $\mathrm{NaCl}$ or-in one case- $\mathrm{KCl}$ was added in different amounts (Table 1). For most syntheses $50-55 \mathrm{mg}$ oxide mixtures and $10-15 \mathrm{mg} \mathrm{H}_{2} \mathrm{O}$ were sealed in a Pt-capsule with an outer (inner) diameter of $4.0(3.6) \mathrm{mm}$. In the most $\mathrm{NaCl}$-rich synthesis run $\mathrm{RS} 122$ only $4.5 \mathrm{mg} \mathrm{H}_{2} \mathrm{O}$ was added. All syntheses were performed in an end-loaded piston cylinder apparatus at $25 \mathrm{kbar}$ and temperatures decreasing from 1,400 to $1,150^{\circ} \mathrm{C}$ with a rate of $10-11^{\circ} / \mathrm{h}$. When the final temperature was reached, the run was terminated by switching off the power.

After the run all charges were weighed, pierced and the $\mathrm{pH}$ of the extruding fluid was checked with indicator paper. The checked fluid was in all cases neutral to slightly alcalic ( $\mathrm{pH}=7-9)$. Subsequently, the pierced capsules were dried in an oven at $110-120^{\circ} \mathrm{C}$, whereupon salt crystals formed at the opening of the capsule. Run products of the dried charges consisted of large orthopyroxene crystals (up to $1 \mathrm{~mm}^{3}$ ), amorphous silicate quench material and salt crystals.

From each experimental charge 2 of the largest crystals were handpicked and orientated by their optical properties parallel (100) and (010) in a thermoplastic resin, and ground and polished (Table 1). After preparation the dimensions of the cuboids were between $150 \times 230 \times 900 \mu \mathrm{m}$ and $390 \times 480 \times 2,000 \mu \mathrm{m}$. In two cases (i.e. run RS118 and RS122) the size of the synthesized crystals turned out to be too small to allow alignment of individual crystals parallel (100) and (010). Therefore two wafers-one parallel (100) and one parallel (010) — were prepared. The thickness of these wafers was between 70 and $180 \mu \mathrm{m}$.

Polarised IR-spectra were recorded on each polished crystal face parallel to the main refractive indices $n_{\alpha}, n_{\beta}$ and $n_{\gamma}$ in transmitted light. All IR measurements were performed with a Perkin Elmer 2000 FTIR-spectrometer coupled to an IR microscope. Measurements were taken using a MIR globar light source, a $\mathrm{KBr}$ beamsplitter, a $\mathrm{MCT}$-detector and a wire-grid polarizer. For each spectrum $100-300$ scans in the 1,000 and $5,000 \mathrm{~cm}^{-1}$ range were acquired with a spectral resolution of $4 \mathrm{~cm}^{-1}$. In contrast to Stalder (2004) and Stalder et al. (2005) background corrections were carried out by adjusting a polynomial baseline at 2,750-2,980, 3,250-3,300 and 3,450$3,750 \mathrm{~cm}^{-1}$. In this way, the broad absorbance feature centered at approximately $3,250 \mathrm{~cm}^{-1}$ was excluded for quantification of water, leading to lower water contents and spectra comparable to Grant et al. (2006). H-contents (Table 1) were quantified by adding the $\alpha-, \beta$ - and $\gamma$-components of the background corrected polarised measurements using the calibration of Libowitzky and Rossman (1997).

After IR measurements all crystals were embedded in epoxy and were analysed with a JEOL JXA 8900 RL

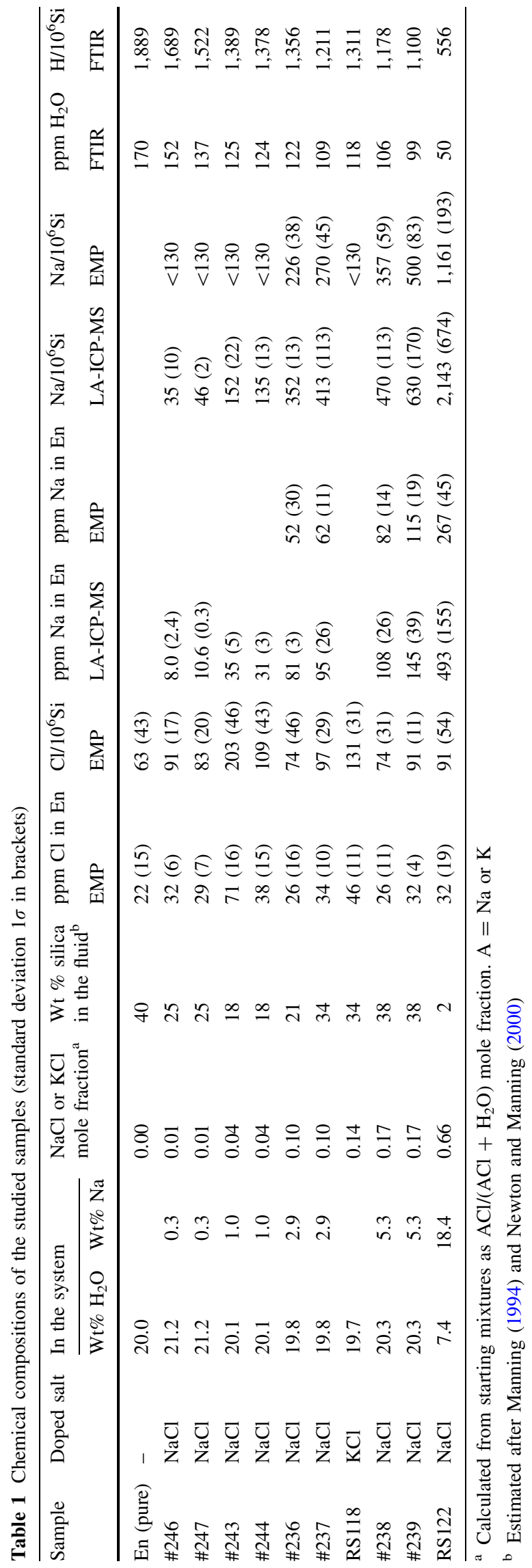


electron microprobe using an accelerating voltage of $15 \mathrm{kV}$ and a beam current of $30 \mathrm{nA}$. Albite, olivine and $\mathrm{NaCl}$ were used as standards. For $\mathrm{Si}$ and $\mathrm{Mg}$ the analysis time lasted $15 \mathrm{~s}$ on the peak and $5 \mathrm{~s}$ on the background, for $\mathrm{Na}$ and $\mathrm{Cl}$ the analysis time lasted $150 \mathrm{~s}$ on the peak and $75 \mathrm{~s}$ on the background on $\mathrm{K}_{\alpha}$ emission lines. Five to ten points were measured on each crystal. All analysed crystals were stoichiometric within analytical error. Results for $\mathrm{Na}$ and $\mathrm{Cl}$ are given in Table 1. Detection limits calculated on the basis of counting statistics of the background signals were $30 \mathrm{ppm}$ for $\mathrm{Na}$ and $10 \mathrm{ppm}$ for $\mathrm{Cl}$.

In order to get more information about the alkali content of the alkali-poor crystals, samples were also analysed by LA-ICP-MS. ${ }^{23} \mathrm{Na},{ }^{29} \mathrm{Si},{ }^{35} \mathrm{Cl},{ }^{37} \mathrm{Cl}$ and ${ }^{39} \mathrm{~K}$ were measured using a Perkin Elmer DRC II (Sciex, Canada) equipped with a GeoLas Laserablation system (Mikrolas, Göttingen) and a 193 nm Excimer Laser (Lambda Physik, Göttingen). Ar-gas was used to transport laser ablation aerosols into the ICP-MS. Results are given in Table 1.

\section{Results}

IR-spectra show for all samples absorption bands at the same position $\left(3,360\right.$ and $\left.3,070 \mathrm{~cm}^{-1}\right)$, but with different intensity. The positions of the observed absorption bands are identical to the positions in pure (Na-free) enstatite (Fig. 1). The absorbance in different directions follows the order $E / / n_{\gamma} \gg E / / n_{\alpha} \geq E / / n_{\beta}$. In all samples, the $\gamma$-component $\left(E / / n_{\gamma}\right)$ of $\mathrm{OH}$-dipole vectors accounts for $60-70 \%$ of the total absorption.

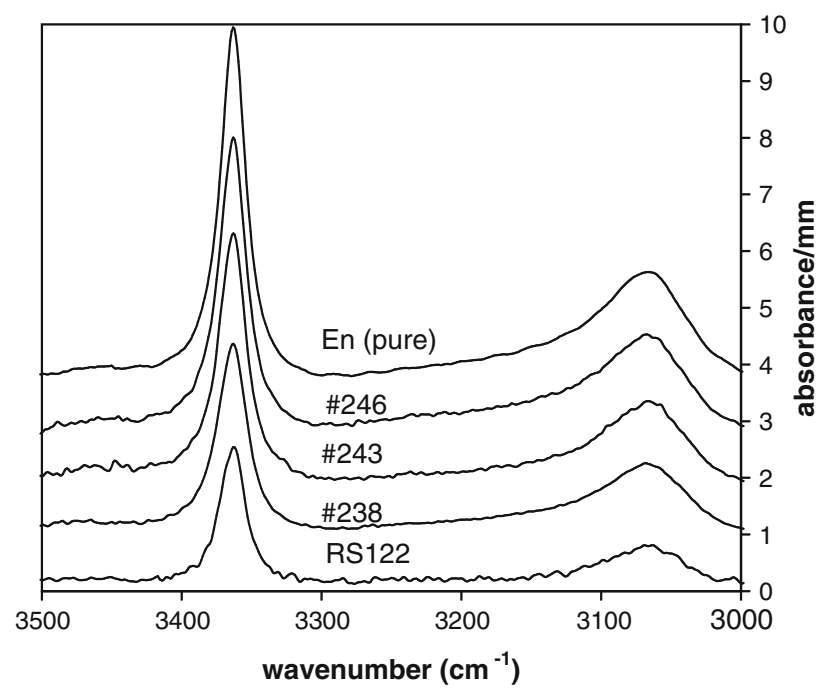

Fig. 1 FTIR-spectra of selected samples synthesized in a broad salinity range (see Table 1). All spectra shown represent the total absorbance of the $\mathrm{OH}$-dipole determined by adding the intensities of the polarised measurements $E / / n_{\alpha}+E / / n_{\beta}+E / / n_{\gamma}$
Na-contents measured by laser ablation-ICP-MS are in quite good agreement with electron microprobe data. In contrast, Cl-contents measured by laser ablation-ICP-MS deviate by approximately 1 order of magnitude from electron microprobe data. The $\mathrm{Cl}$ level determined by electron microprobe is just above the detection limit and no correlation between $\mathrm{Cl}$-content of the start mixture and $\mathrm{Cl}$-content in orthopyroxene could be revealed (Table 1). It has to be noted that even electron microprobe analysis may overestimate the real $\mathrm{Cl}$-concentration of the samples, as some $\mathrm{Cl}$ may have been excited from the epoxy matrix due to secondary fluorescence. Therefore the values measured by electron microprobe should be regarded as upper limit for the real $\mathrm{Cl}$-concentration. This idea is supported by the fact that even in the pure enstatite sample-synthesized in a nominally $\mathrm{Cl}$-free system-a similar level of $\mathrm{Cl}$ is revealed (Table 1). Laser ablation-ICP-MS is not the method of choice to analyse low-level concentrations of chlorine, but the exact reason for the elevated measured $\mathrm{Cl}$ concentrations could not be revealed. Possible explanations are (1) volatilisation from the epoxy during ablation and/or (2) matrix effects. As the Cl-content of nearly all samples is within analytical error constant and independent on the Na-content, a continuous low-level leakage from fluid inclusions as $\mathrm{Cl}$-source can be excluded. Though, laser ablation turned out to be a valuable tool for detecting $\mathrm{NaCl}$-rich inclusions. Solid $\mathrm{NaCl}$ inclusions in the synthetic crystals have not been observed under the microscope, but can be inferred from the laser ablationICP-MS signal (Fig. 2). In nearly all samples the time resolved ablation signal shows a homogeneous $\mathrm{NaCl} / \mathrm{Si}$ ratio (Fig. 2a). Only in the most $\mathrm{NaCl}$-rich run, a simultaneous $\mathrm{Na}$ - and $\mathrm{Cl}$-increase at constant $\mathrm{Si}$-signal could be observed (Fig. 2b), suggesting ablation of $\mathrm{NaCl}$-inclusions or $\mathrm{NaCl}$-rich brines in the enstatite crystal.

$\mathrm{K}$ was for all laser ablation-ICP-MS analyses below the detection limit ( $<10$ wt. ppm).

\section{Discussion}

\section{Reduction of $\mathrm{H}$-incorporation}

There are several possible factors to explain the reduced $\mathrm{H}$ incorporation with increasing salt content in the system: (1) $\mathrm{OH}^{-}$is replaced by $\mathrm{Cl}^{-}$, (2) $\mathrm{Na}^{+}$affects the defect chemistry, and (3) the water fugacity is reduced due to the dissolved salt.

Cl-concentrations in enstatite determined by electron microprobe do not exhibit a significant trend over a broad range of $\mathrm{NaCl}$ in the system (Table 1). Therefore, a replacement of $\mathrm{OH}^{-}$by $\mathrm{Cl}^{-}$cannot account for the strong decrease in $\mathrm{H}$-content with increasing $\mathrm{NaCl}$ in the system. 

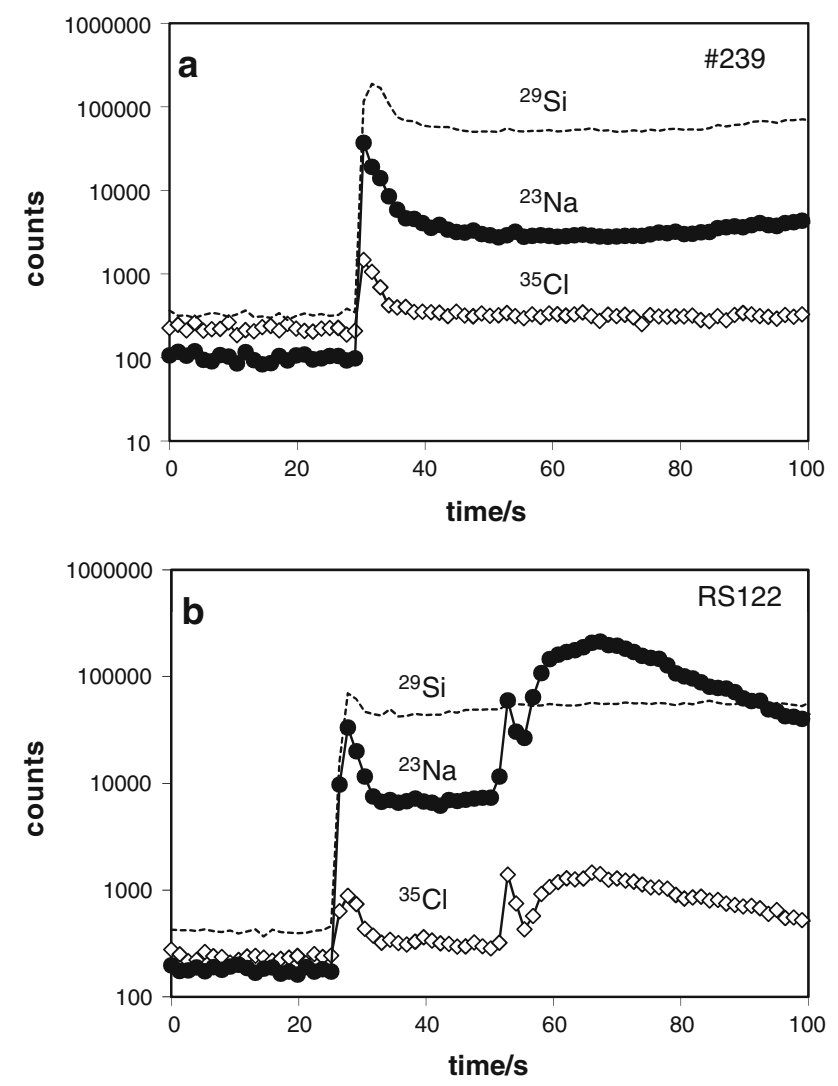

Fig. 2 Time resolved laser ablation-ICP-MS signal for crystals without (a) and with (b) NaCl- or NaCl-rich fluid inclusions. In the latter case only the inclusion-free part (in this case between 30 and $50 \mathrm{~s}$ ) was used for calculating the Na-content of the sample

In addition, $\mathrm{Cl}$-concentrations are generally too low to allow a significant exchange of $\mathrm{OH}^{-}$and $\mathrm{Cl}^{-}$. Thirty-five wt ppm $\mathrm{Cl}$ correspond to $100 \mathrm{Cl} / 10^{6} \mathrm{Si}$, which is more than an order of magnitude less than the observed change in $\mathrm{H} / 10^{6} \mathrm{Si}$ (Table 1).

From the IR spectra it is evident that all samples host the same type of $\mathrm{OH}$-defects, suggesting that $\mathrm{Na}^{+}$does not contribute to the generation of new $\mathrm{OH}$-defect associates (i.e. defects which are not already existing in pure enstatite). In contrast, the negative correlation between the $\mathrm{H}$-content and the Na-content in enstatite (Fig. 3) may be interpreted in a way that $\mathrm{Na}^{+}$concurs with $\mathrm{H}^{+}$during charge balancing of the $\mathrm{Mg}$-vacancies. This is, however, not very probable, since $\mathrm{KCl}$ causes a reduction in $\mathrm{H}$-content similar to $\mathrm{NaCl}$. In RS118 K was below detection limit and therefore (by mole) at least one order of magnitude less abundant than $\mathrm{Na}$ in runs with comparable $\mathrm{NaCl}$ concentrations in the starting mixture. Therefore the influence on $\mathrm{Na}^{+}$on $\mathrm{H}$-incorporation in enstatite can be neglected.

The only remaining important mechanism for the decreased $\mathrm{H}$-incorporation is the reduced water activity due to dissolved salt (Fig. 4). It has to be stressed that-as far

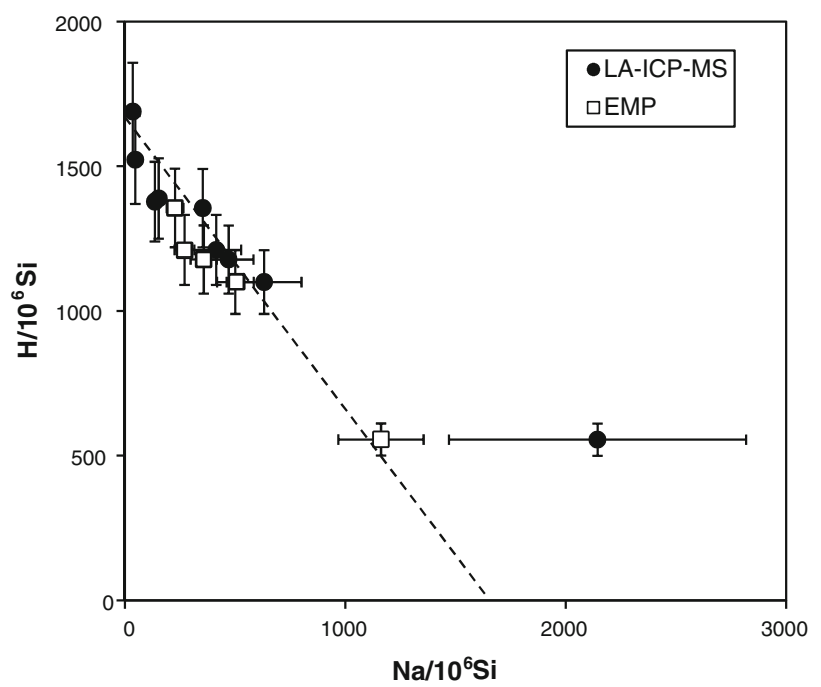

Fig. 3 Hydrogen contents determined by FTIR versus Na contents (determined by laser ablation-ICP-MS and by electron microprobe) of all enstatite crystals

as the nature of the fluid is concerned-there are several unknowns in this study. The solubilities of oxide components in the highly saline fluid are not known and therefore it is not clear, whether aqueous fluid and hydrous melt behave supercritical under the conditions of synthesis. In the case of subcritical behaviour, partition coefficients between aqueous saline fluid and hydrous melt are not known either. The pure system $\mathrm{SiO}_{2}-\mathrm{H}_{2} \mathrm{O}$ would behave supercritical (Kennedy et al. 1962) under the final synthesis conditions (i.e. $25 \mathrm{kbar}, 1,150^{\circ} \mathrm{C}$ ), and approximately $40 \mathrm{wt} \%$ silica would be soluble in the fluid (Manning 1994). However, addition of salt at high pressure reduces the silica content of the fluid (Newton and Manning 2000) and may open the miscibility gap between aqueous fluid and hydrous melt. From the results of the experimental work of Newton and Manning (2000) it can be estimated that an increase of $X_{\mathrm{NaCl}}$ by 0.1 results in a decrease of silica molality in the fluid of $0.2 \log$ units. Furthermore, as silica is mainly dissolved as dimer $\left(\mathrm{H}_{6} \mathrm{Si}_{2} \mathrm{O}_{7}\right)$ in high pressure fluid phases (Zotov and Keppler 2002; Newton and Manning 2003), the mole fraction of $\mathrm{H}_{2} \mathrm{O}$ would for all experimental runs be only moderately shifted towards lower values. Therefore, only $\mathrm{H}_{2} \mathrm{O}$ and the amount of $\mathrm{NaCl}$ (or $\mathrm{KCl}$ ) added to the system was considered for calculating the $\mathrm{H}_{2} \mathrm{O}$ mole fraction. The strong initial decline in hydrogen incorporation (Fig. 4) with increasing salinity (decreasing water mole fraction) is independent on the added salt, supporting the above made conclusion that $\mathrm{Na}-$ incorporation has only very limited influence on hydrogen incorporation in enstatite (at least in the studied system, where no trivalent cations are present). From $\mathrm{H}_{2} \mathrm{O}$ mole fractions, water activities were calculated by two 


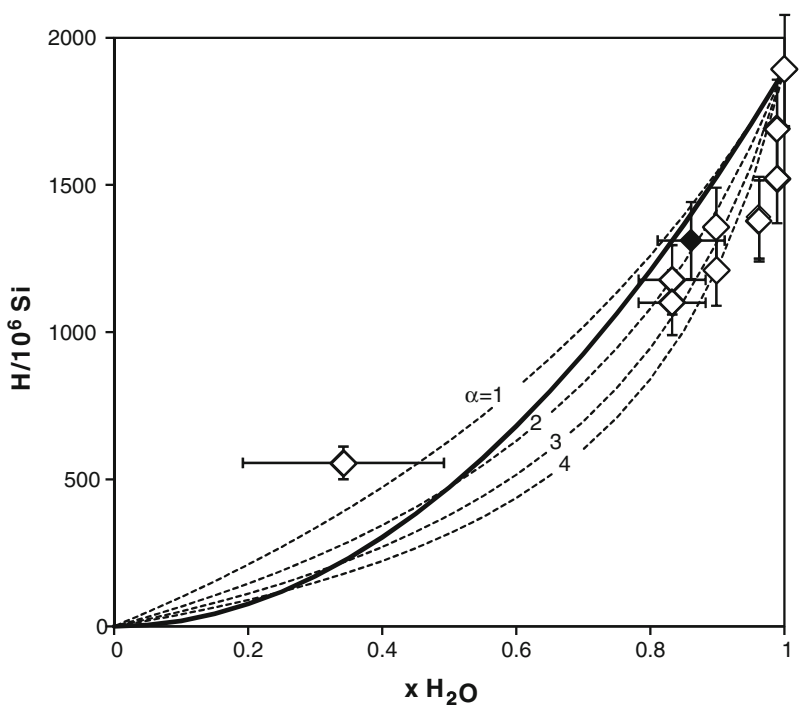

Fig. 4 Influence of the mole fraction of water in the fluid on the hydrogen content in enstatite determined by FTIR. The mole fraction of water was calculated assuming one homogeneous fluid containing the whole inventory of the added salt component. Dissolved silica was not taken into account. The solid symbol represents the run conducted with $\mathrm{KCl}$ instead of $\mathrm{NaCl}$. The trend lines show the expected drop in water activity by the model of Aranovich and Newton (1997) (solid line), and the ideal-fused-salt model (Bradley 1962) accounting for varying degree of ionization $\alpha$ of $\mathrm{NaCl}$ (thin dotted lines) and ideal mixing of $\mathrm{Na}^{+}$and $\mathrm{Cl}^{-}$ions with $\mathrm{H}_{2} \mathrm{O}$ molecules. Curves are labelled with the respective value for $\alpha$

models: (1) $\mathrm{H}_{2} \mathrm{O}$ activity is equal to the square of its mole fraction (Aranovich and Newton 1997), and (2) the ideal-fused-salt model involving fully dissociated $\mathrm{NaCl}$ and ideal mixing of $\mathrm{Na}^{+}$and $\mathrm{Cl}^{-}$ions with $\mathrm{H}_{2} \mathrm{O}$ molecules (Bradley 1962; Newton and Manning 2006), where $a_{\mathrm{H}_{2} \mathrm{O}}=\left(1-X_{\mathrm{NaCl}}\right) /\left(1+X_{\mathrm{NaCl}}\right)$. The latter model has been modified taking into account varying degree of ionization $\alpha$ of $\mathrm{NaCl}$, leading to $a_{\mathrm{H}_{2} \mathrm{O}}=\left(1-X_{\mathrm{NaCl}}\right) /\left(1+\alpha X_{\mathrm{NaCl}}\right)$ (Aranovich and Newton 1996), where the degree of ionization depends on the density of water under run conditions. $\rho \mathrm{H}_{2} \mathrm{O}$ was obtained by extrapolation from Halbach and Chatterjee (1982). For $25 \mathrm{kbar}$ and $1,150^{\circ} \mathrm{C}$ we obtain $\rho \mathrm{H}_{2} \mathrm{O}=1.075 \mathrm{~g} / \mathrm{m}^{3}$, leading to $\alpha=1.46$. Using this parameter we obtain-except for the most water-rich samples - a fair accordance to the experimental data points (Fig. 4). The mismatch of the most water-poor data point may be due to its location above the salt saturation level (salt inclusions have been detected during laser ablation analysis, Fig. 2), and its actual $\mathrm{H}_{2} \mathrm{O}$ mole fraction of may be higher. It may also be possible that $\alpha$ changes with mole fraction from initially high values at pure water towards smaller values at higher salt concentrations, which would both explain the sudden decrease of water in enstatite at low $\mathrm{NaCl}$ mole fractions and the positive deviation of the data point at high $\mathrm{NaCl}$ mole fraction.
Element partitioning

It is not known, whether at synthesis conditions a hydrous melt coexists with an aqueous fluid or whether one homogeneous fluid exists. Therefore, there are several ways to estimate the partitioning behaviour of $\mathrm{Na}$ and $\mathrm{H}$. A lower estimate for the partition coefficient $D_{\mathrm{Na}}^{\mathrm{En} / \mathrm{Fl}}$ can be obtained, if it is considered that a highly saline aqueous fluid, which contains most of the $\mathrm{Na}$ and $\mathrm{Cl}$ in the system, is coexisting with a silicate melt. The partitioning of $\mathrm{Na}$ between enstatite and fluid can then be calculated, considering the silica content dissolved in the aqueous fluid at $25 \mathrm{kbar}$ and $1,150^{\circ} \mathrm{C}$ (Table 1) based on the experimental results of Manning (1994) and Newton and Manning (2000). The obtained value $D_{\mathrm{Na}}^{\mathrm{En} / \mathrm{Fl}}=0.0013$ (Fig. 5) is significantly higher than $D_{\mathrm{H}}^{\mathrm{En} / \mathrm{Fl}}=0.0003\left(1889 \mathrm{H} / 10^{6} \mathrm{Si}\right.$ corresponding to 170 wt ppm $\mathrm{H}_{2} \mathrm{O}$ in enstatite, divided by $60 \mathrm{wt} \% \mathrm{H}_{2} \mathrm{O}$ in the fluid). An upper estimate for element partitioning can be performed, if the bulk starting composition of each run is compared to $\mathrm{Na}$ and $\mathrm{H}$ content of the synthesized crystals. In this case slightly higher partition coefficients (i.e. $D_{\mathrm{Na}}^{\text {En/Startmix }}=0.0027, D_{\mathrm{H}}^{\text {En/Startmix }}=$ 0.0006) are obtained (Fig. 5), but the ratio of the two coefficients stays the same. This means that $\mathrm{Na}$ is much more compatible in enstatite than $\mathrm{H}$, which substantiates the above made conclusion that - at its best—only a small fraction of the incorporated $\mathrm{Na}^{+}$-ions actually compensate $\mathrm{OH}$-defects in the enstatite lattice and by far most of the $\mathrm{Na}^{+}$has to be incorporated by another substitution

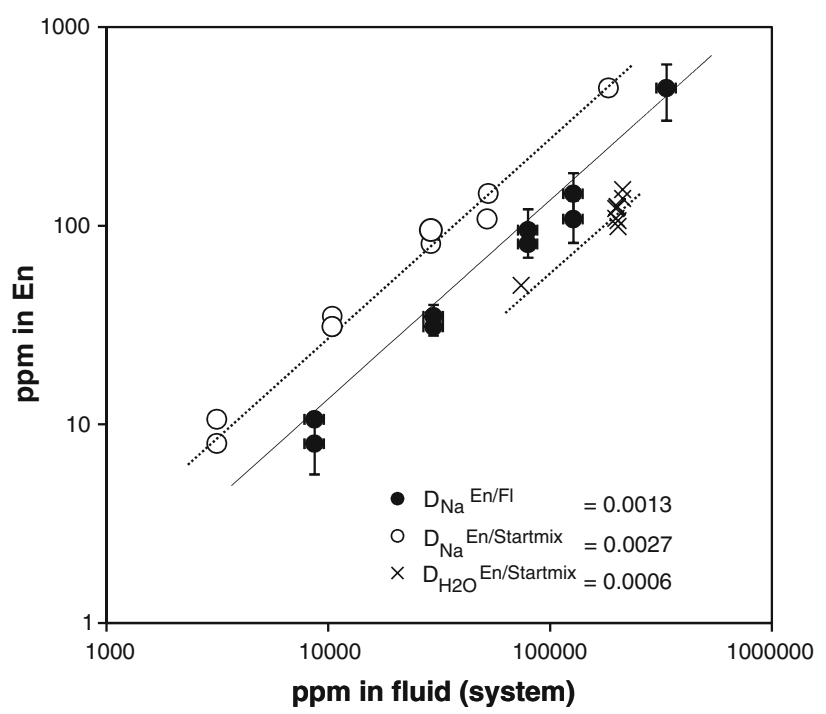

Fig. $5 \mathrm{Na}$ partitioning and $\mathrm{H}_{2} \mathrm{O}$ partitioning between enstatite and fluid. $\mathrm{Na}$ concentrations in enstatite were determined by laser ablation-ICP-MS. Na concentrations in the fluid were calculated assuming one homogeneous fluid containing the whole inventory of the added salt component and a dissolved silica component (Table 1) estimated from the studies of Manning (1994) and Newton and Manning (2000) 
mechanism. It can, however, be excluded that $\mathrm{Na}$ is incorporated as $\mathrm{NaCl}$ or $\mathrm{NaCl}$-fluid inclusions, since there is no apparent correlation between the $\mathrm{Na}$ - and the $\mathrm{Cl}$-content of the enstatite crystals.

An upper limit for Cl-partitioning can also be estimated from the results of the most $\mathrm{Cl}$-rich run $\mathrm{RS} 122$. Considering electron microprobe results (Table 1) as upper limit for the real $\mathrm{Cl}$ incorporated into the enstatite lattice, $D_{\mathrm{Cl}}^{\mathrm{En} / \mathrm{Fl}}$ is at least one order of magnitude lower than $D_{\mathrm{Na}}^{\mathrm{En} / \mathrm{Fl}}$. This means that $\mathrm{Cl}$ is the most incompatible volatile in our study, in good agreement to estimates based on natural systems (Saal et al. 2002; Straub and Layne 2003).

Implications for the Earth's mantle

Estimates for the total concentration of chlorine in the upper mantle range from $1 \mathrm{ppm}$ for depleted MORB mantle (Saal et al. 2002) to 17 ppm for pyrolite (McDonough and Sun 1995), where a large proportion of the subducted chlorine is transferred to the mantle reservoir (Philippot et al. 1998). Models for the global chlorine cycle suggest a balance between input through subduction and output through magmatism (Ito et al. 1983; Straub and Layne 2003). With respect to chlorine, the results of our study are somewhat speculative. However, the most saltrich experimental run of our experiments (RS122), where solid $\mathrm{NaCl}$-inclusions have been inferred, sets an upper estimate (i.e. $30 \mathrm{ppm}$ ) for $\mathrm{Cl}$-incorporation in enstatite at $25 \mathrm{kbar}$ and $1,150^{\circ} \mathrm{C}$. This value is similar to the $\mathrm{Cl}$-content of an orthopyroxene from a high pressure metamorphic $\left(>700^{\circ} \mathrm{C}, 18 \mathrm{kbar}\right)$ harzburgite converted from an antigorite serpentinite during subduction metamorphism (Scambelluri et al. 2004), where 25 ppm Cl were detected. Considering the limited $\mathrm{Cl}$ incorporation in our experiments even at salt saturation, orthopyroxene does not seem to be a major host for $\mathrm{Cl}$ in the mantle, unless $\mathrm{Cl}$ is incorporated as fluid inclusions (Philippot et al. 1998).

On the other hand, the results of our study imply that $\mathrm{H}$ incorporation in nominally anhydrous minerals in $\mathrm{NaCl}$ rich portions of the mantle (e.g. subduction settings) may be more limited than previously thought. Low water contents in pyroxenes from the sub-arc mantle wedge have previously been interpreted to be controlled by the redox state of the mantle rock (Peslier et al. 2002), since a negative correlation between oxygen fugacity and water content of the pyroxenes could be established. On the basis of our experimental results the salinity of the fluid phase could be an alternative explanation. This aspect has so far not been investigated in natural samples and deserves further scrutiny. Furthermore, it has to be taken into consideration that water incorporation in orthopyroxene is strongly enhanced by the presence of trivalent cations, such as $\mathrm{Al}^{3+}$ (Stalder, 2004; Mierdel et al. 2007). For natural orthopyroxenes, in which these cations usually reach high concentrations (e.g. typically up to several wt $\mathrm{Al}_{2} \mathrm{O}_{3}$ ), the presence of monovalent cations, such as $\mathrm{Na}^{+}$, may have a negative effect on the water storage capacity.

Acknowledgments Simon Kohn and an anonymous reviewer are thanked for their constructive reviews, which helped to improve this article.

Open Access This article is distributed under the terms of the Creative Commons Attribution Noncommercial License which permits any noncommercial use, distribution, and reproduction in any medium, provided the original author(s) and source are credited.

\section{References}

Aranovich LY, Newton RC (1996) $\mathrm{H}_{2} \mathrm{O}$ activity in concentrated $\mathrm{NaCl}$ solutions at high pressures and temperatures measured by the brucite-periclase equilibrium. Contrib Mineral Petrol 125:200212

Aranovich LY, Newton RC (1997) $\mathrm{H}_{2} \mathrm{O}$ activity in concentrated $\mathrm{KCl}$ and $\mathrm{KCl}-\mathrm{NaCl}$ solutions at high temperatures and pressures measured by the brucite-periclase equilibrium. Contrib Mineral Petrol 127:261-271

Bell DR, Rossman GR (1992) Water in the Earth's mantle: the role of nominally anhydrous minerals. Science 255:1391-1397

Bradley RS (1962) Thermodynamic calculations on phase equilibria involving fused salts. Part I. General theory and application to equilibria involving calcium carbonate at high pressure. Am J Sci 260:374-382

Grant K, Kohn SC, Brooker RA (2006) Solubility and partitioning of water in synthetic forsterite and enstatite in the system MgO$\mathrm{SiO}_{2}-\mathrm{H}_{2} \mathrm{O} \pm \mathrm{Al}_{2} \mathrm{O}_{3}$. Contrib Mineral Petrol 151:651-664

Grant K, Ingrin J, Lorand JP, Dumas P (2007) Water partitioning between mantle minerals from peridotite xenoliths. Contrib Mineral Petrol 154:15-34

Halbach H, Chatterjee ND (1982) An empirical Redlich-Kwong-type equation of state for water to $1000^{\circ} \mathrm{C}$ and $200 \mathrm{kbar}$. Contrib Mineral Petrol 79:337-345

Ingrin J, Skogby H (2000) Hydrogen in nominally anhydrous uppermantle minerals: concentration levels and implications. Eur J Mineral 12:543-570

Ito E, Harris DM, Anderson AT (1983) Alteration of oceanic crust and geologic cycling of chlorine and water. Geochim Cosmochim Acta 47:1613-1624

Karato S (1990) The role of hydrogen in the electrical conductivity of the upper mantle. Nature 347:272-273

Kennedy GC, Wasserburg GJ, Heard HC, Newton RC (1962) The upper three-phase region in the system $\mathrm{SiO}_{2}-\mathrm{H}_{2} \mathrm{O}$. Am J Sci 260:501-521

Kitamura M, Kondoh S, Morimoto N, Miller GH, Rossman GR, Putnis A (1987) Planar OH-bearing defects in mantle olivine. Nature 328:143-145

Libowitzky E, Rossman GR (1997) An IR absorption calibration for water in minerals. Am Mineral 82:1111-1115

Mackwell SJ, Kohlstedt DL, Paterson MS (1985) The role of water in the deformation of olivine single crystals. J Geophys Res 90:11319-11333

Manning CE (1994) The solubility of quartz in $\mathrm{H}_{2} \mathrm{O}$ in the lower crust and upper mantle. Geochim Cosmochim Acta 58:4831-4839

McDonough WF, Sun SS (1995) The composition of the earth. Chem Geol 120:223-253 
Mei S, Kohlstedt DL (2000) Influence of water on plastic deformation of olivine aggregates 1. Diffusion creep regime. J Geophys Res 105:21457-21469

Mierdel K, Keppler H, Smyth JR, Langenhorst F (2007) Water solubility in aluminous orthopyroxene and the origin of Earth's asthenosphere. Science 315:364-368

Newton RC, Manning CE (2000) Quartz solubility in $\mathrm{H}_{2} \mathrm{O}-\mathrm{NaCl}$ and $\mathrm{H}_{2} \mathrm{O}-\mathrm{CO}_{2}$ solutions at deep crust-upper mantle pressures and temperatures: $2-15 \mathrm{kbar}$ and $500-900^{\circ} \mathrm{C}$. Geochim Cosmochim Acta 64:2993-3005

Newton RC, Manning CE (2003) Activity coefficient and polymerization of aqueous silica at $800^{\circ} \mathrm{C}, 12 \mathrm{kbar}$, from solubility measurements on $\mathrm{SiO}_{2}$-buffering mineral assemblages. Contrib Mineral Petrol 146:135-143

Newton RC, Manning CE (2006) Solubilities of corundum, wollastonite and quartz in $\mathrm{H}_{2} \mathrm{O}-\mathrm{NaCl}$ solutions at $800^{\circ} \mathrm{C}$ and $10 \mathrm{kbar}$ : Interaction of simple minerals with brines at high pressure. Geochim Cosmochim Acta 70:5571-5582

Peslier AH, Luhr JF, Post J (2002) Low water contents in pyroxenes from spinel-peridotites of the oxidized, sub-arc mantle wedge. Earth Planet Sci Lett 201:69-86

Philippot P, Agrinier P, Scambelluri M (1998) Chlorine cycling during subduction of altered oceanic crust. Earth Planet Sci Lett 161:33-44

Rauch M, Keppler H (2002) Water solubility in orthopyroxene. Contrib Mineral Petrol 143:525-536

Saal AE, Hauri EH, Langmuir CH, Perfit MR (2002) Vapour undersaturation in primitive mid-ocean-ridge basalt and the volatile content of the Earth's upper mantle. Nature 419:451-455
Scambelluri M, Piccardo GB, Philippot P, Robbiano A, Negretti L (1997) High salinity fluid inclusions formed from recycled seawater in deeply subducted alpine serpentinite. Earth Planet Sci Lett 148:485-500

Scambelluri M, Müntener O, Ottolini L, Pettke TT, Vannucci R (2004) The fate of $\mathrm{B}, \mathrm{Cl}$ and $\mathrm{Li}$ in the subducted oceanic mantle and in the antigorite breakdown fluids. Earth Planet Sci Lett 222:217-234

Stalder R (2002) Synthesis of enstatite single crystals at high pressure. Eur J Mineral 14:637-640

Stalder R (2004) Influence of $\mathrm{Fe}, \mathrm{Cr}$ and $\mathrm{Al}$ on hydrogen incorporation in orthopyroxene. Eur J Mineral 16:703-711

Stalder R, Klemme S, Ludwig T, Skogby H (2005) Hydrogen incorporation in orthopyroxene: interaction of different trivalent cations. Contrib Mineral Petrol 150:473-485

Straub SM, Layne GD (2003) The systematics of chlorine, fluorine, and water in Izu arc front volcanic rocks: implications for volatile recycling in subduction zones. Geochim Cosmochim Acta 67:4179-4203

Wang D, Mookherjee M, Xu Y, Karato S (2006) The effect of water on the electrical conductivity of olivine. Nature 443:977-980

Yoshino T, Matsuzaki T, Yamashita S, Katsura T (2006) Hydrous olivine unable to account for conductivity anomaly at the top of the asthenosphere. Nature 443:973-976

Zotov N, Keppler H (2002) Silica speciation in aqueous fluids at high pressures and high temperatures. Chem Geol 184:71-82 